\title{
Large-scale field tests on impulse
}

\section{waves}

\section{Conference Paper}

Author(s):

Sauter, Eva; Fuchs, Helge; Schmocker, Lukas; Volkwein, Axel; Prohaska, Yuri; Boes, Robert (D)

Publication date:

2019-09

Permanent link:

https://doi.org/10.3929/ethz-b-000373715

Rights / license:

In Copyright - Non-Commercial Use Permitted 


\title{
LARGE-SCALE FIELD TESTS ON IMPULSE WAVES
}

\author{
Eva Sauter ${ }^{(1)}$, Helge Fuchs ${ }^{(1)}$, Lukas Schmocker(1), Axel Volkwein(2), Yuri Prohaska( ${ }^{(3)}$, Robert M. Boes ${ }^{(1)}$ \\ (1) Laboratory of Hydraulics, Hydrology and Glaciology (VAW), Swiss Federal Institute of Technology Zurich, \\ Zurich, Switzerland \\ schmocker@vaw.baug.ethz.ch \\ (2) Pfeifer Isofer AG, Knonau, Switzerland (formerly WSL) \\ (3) Axpo Holding AG, Baden, Switzerland (formerly VAW, ETH Zürich)
}

\begin{abstract}
Reservoirs and other hydropower infrastructure in mountainous areas have to deal with various natural hazards. Ice- and rockfalls, landslides as well as rock and snow avalanches may impinge the reservoir, generating impulse waves that may overtop dams. Due to climate change and the rise of the permafrost base, the landslide and rockfall hazard is likely to increase in the future. A reliable risk analysis regarding potential impulse waves is therefore inevitable for the hazard assessment of hydropower infrastructure. The existing computational procedures to calculate wave heights and run-up are mostly based on small-scale model tests and may therefore exhibit scale effects. In addition, the uncertainty of the calculated wave height and run-up is still high. Therefore, new data on impulse wave characteristics were collected using large-scale field tests. A test site was established in a $30 \mathrm{~m}$ deep gravel pit. The artificial reservoir was $15 \mathrm{~m}$ wide, $55 \mathrm{~m}$ long and had a still water depth of $1.5 \mathrm{~m}$. A $40 \mathrm{~m}$ long steel ramp along the pit slope $\left(37^{\circ}\right)$ provided a sliding surface. The sliding mass was represented by a steel sledge ( 3 to 7 tons). The sledge could be released from different ramp positions to vary the impact velocity between 6 and $17 \mathrm{~m} / \mathrm{s}$. The resulting wave heights along the wave propagation path and the wave run-up were visually determined using gauge poles. The results help to (1) improve existing computational procedures, (2) determine possible scale effects; and (3) serve as calibration and validation data for numerical modelling of impulse waves.
\end{abstract}

Keywords: Climate change, Field tests, Impulse waves, Natural hazards, Prototype data, Scale effects

\section{INTRODUCTION}

Operators of hydropower (HP) infrastructure and reservoirs in the alpine environment have to deal with various natural hazards. Among them, ice- and rockfalls, landslides as well as rock and snow avalanches may impinge a reservoir, generating impulse waves that may overtop or even damage and breach dams. The overtopping water can lead to hazardous flood waves that propagate downstream through densely populated valleys. Due to climate change and the rise of the permafrost base, the landslide and rockfall hazard will likely increase in the future. Furthermore, glacier retreat enables new reservoirs in high mountainous environments (Ehrbar et al. 2018), which are increasingly prone to be hit by avalanches or landslides. An overview on past events of impulse wave hazards can be found in Evers (2017). A reliable risk assessment regarding potential impulse waves is therefore inevitable for the hazard assessment of a HP infrastructure. This assessment is generally carried out in three steps. Step 1 includes the definition of potential landslide, rockfall or avalanche volumes, their propagation pathways impact characteristics when impinging the reservoir. In step 2, the wave generation and propagation is modelled. Step 3 deals with the estimation of the wave run-up and the impact 
on hydraulic structures. Whereas step 1 may be covered with well-established slide-models based on field data, steps 2 and 3 are currently still challenging and contain large uncertainties.

Impulse wave features in reservoirs and the likelihood of dam overtopping can be evaluated by a computational procedure established by Heller et al. (2009). This procedure is primarily based on laboratoryscale model tests conducted in the $1 \mathrm{~m}$ deep, $0.5 \mathrm{~m}$ wide and $11 \mathrm{~m}$ long impulse wave channel at the Laboratory of Hydraulics, Hydrology and Glaciology (VAW) of ETH Zurich (Fritz et al., 2003; Zweifel, 2004; Heller, 2008). A conversion method from these channelized 2D characteristics to a radial 3D wave propagation is included according to Huber and Hager (1997). Spatial wave generation and the corresponding radial wave propagation, as it is mostly the case in real-world situations, was also recently investigated in laboratory scale by Evers (2017). Fuchs (2013) conducted laboratory experiments on impulse wave run-up and the resulting overland flow. Based on experimental data found in literature, Evers and Boes (2019) proposed an universal equation for non-breaking impulse wave runup for relative wave heights from $H / h=0.007$ to 0.69 on slope angles from $10^{\circ}$ to $90^{\circ}$. The overall dataset is predicted within a $20 \%$ scatter.

Alternatively, numerical models can be used to calculate impulse wave features (e.g. Falappi and Gallati 2007). However, these models need calibration and validation data that are often also derived from smallscale model tests and therefore prone to both model and scale effects. Heller et al. (2008) investigated scale effects in granular impulse wave generation and propagation in the above mentioned VAW impulse wave channel with still water depths between $0.1 \mathrm{~m}$ and $0.6 \mathrm{~m}$. They stated a limit still water depth of $0.2 \mathrm{~m}$ to avoid significant scale effects due to water surface tension and viscosity.

For a proper validation of the analytical and numerical procedures, reliable field data on impulse waves or large-scale experiments are still missing. Information on actual impulse waves features are very rare. Measured field data usually only comprise run-up heights. Other wave parameters such as the wave height are back calculated from these observed run-up heights and therefore involve additional uncertainty. The Lituya Bay case of 1958 is one of the few well documented events where field data allowed to establish empirical equations for the wave amplitude (Ataie-Ashtiani and Malek Mohammadi 2007). Despite the enormous hazard potential of impulse waves, large-scale field tests do not exist and field data are currently unavailable, mainly due to the considerable effort for data acquisition. Consequently, the current knowledge of this type of natural hazard remains limited.

Therefore, the present investigation was conducted to collect data on impulse wave characteristics by means of large-scale field tests. An innovative test-setup in a gravel-pit allowed testing of artificially generated impulse waves under controlled conditions. To identify possible scale effects, the field tests were reproduced in a 1:10 model basin in the laboratory. The experimental data further allows for a thorough validation of both the existing computational approach (Heller et al. 2009) and numerical models.

\section{FIELD TESTS}

\section{Experimental facilities}

The field experiments were conducted during a 2-month period at the gravel pit Widstud near the city of Bülach, Canton of Zurich, Switzerland. The rectangular basin was constructed at the bottom of the gravel pit and sealed with a pond liner (Figure 1). The bottom of the test basin is $56 \mathrm{~m}$ long and $10 \mathrm{~m}$ wide. The slide impact angle is $37^{\circ}\left( \pm 0.5^{\circ}\right)$ and the side banks and the run-up bank opposite to the slide impact were constructed to $32.5^{\circ}\left( \pm 2.5^{\circ}\right)$. At the toe of the slide ramp, the bottom was additionally excavated by $\approx 0.85 \mathrm{~m}$ in vertical and $\approx 3.0 \mathrm{~m}$ in streamwise direction to account for the foundation of the sledge guidance system (Fig. 3). The basin was filled with fresh water provided by the city of Bülach to a still water depth of $h \approx 1.50 \mathrm{~m}$ (2.35 $\mathrm{m}$ at the slide ramp toe). The steel ramp was $44 \mathrm{~m}$ long and $3 \mathrm{~m}$ wide. A measurement tape was attached to the ramp to determine the slide distance. 


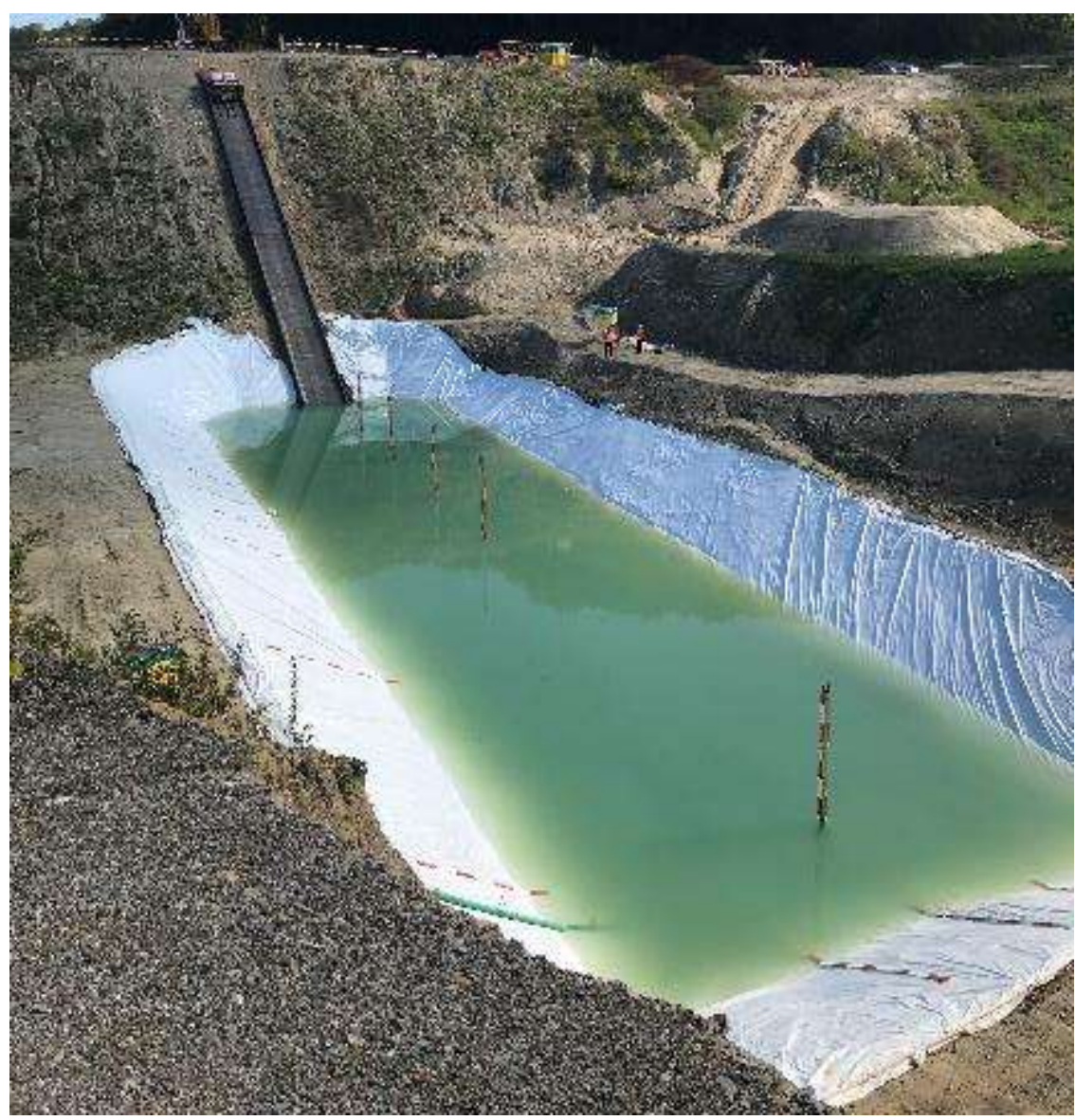

Figure 1. Field test setup at gravel pit in Bülach, Switzerland (people on the right bank for scale)

The slide mass was represented by a $3.0 \mathrm{~m}$ long steel body sledge with a $2.68 \mathrm{~m}$ wide and $1.5 \mathrm{~m}$ high front plate (Figure 2). The steel sledge was equipped with skids and was guided by $0.3 \mathrm{~m}$ high sidewalls along the ramp. The empty weight of the sledge was $3.2 \mathrm{t}$. Four 1'000 liter volume water containers could be filled and placed onto the sledge to increase the total mass up to $7.2 \mathrm{t}$. The sledge could be moved to a desired height on the ramp using a cable winch and was then released by a remote controlled pawl. After release, the sledge accelerated along the slide ramp by gravity. To additionally vary the impact velocity, several tests were carried out with the winch still attached but running idle (Section 2.3). 


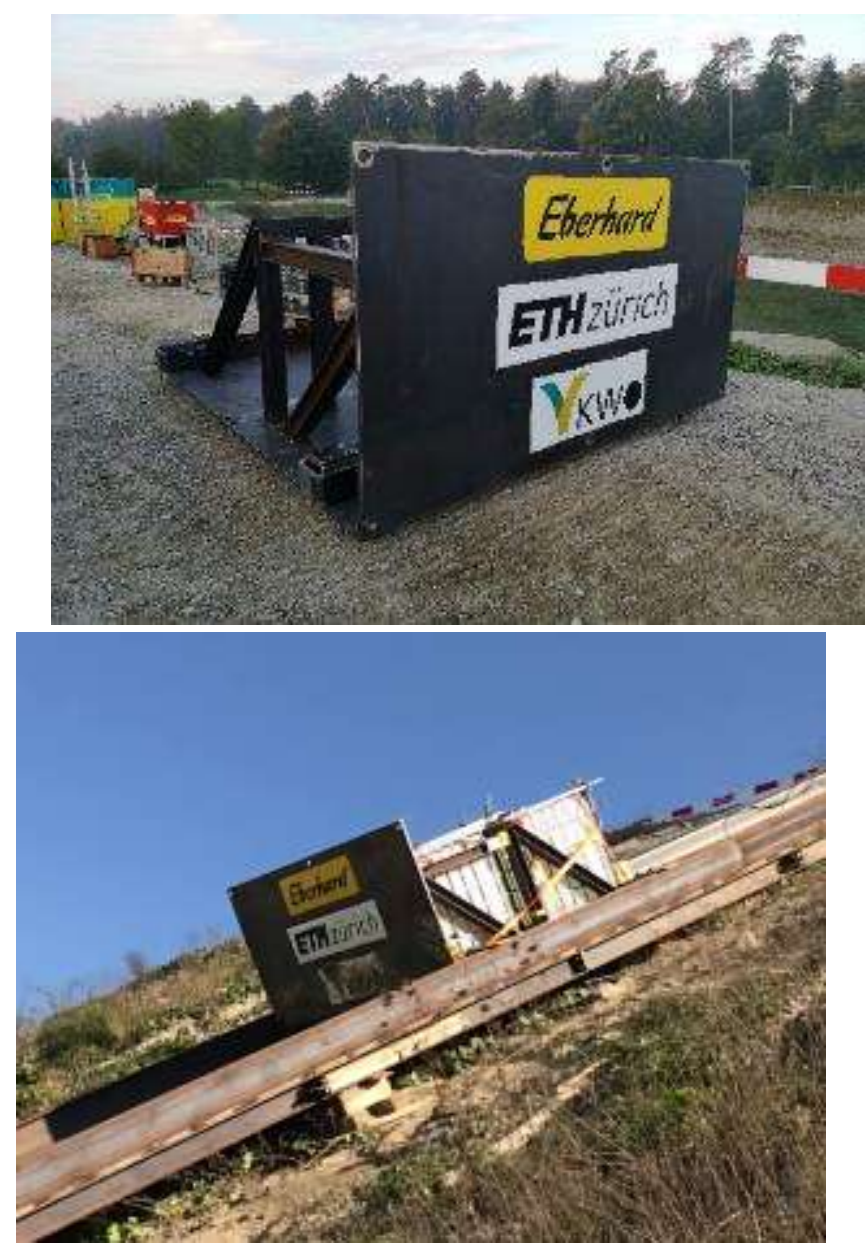

Figure 2. Steel sledge before (left) and after (right) installation on steel ramp

\section{Instrumentation}

The sledge velocity was measured $10 \mathrm{~m}$ above the still water level by two laser sensors located on the ramp. The sensors registered the passing sledge with an acquisition rate of $1 \mathrm{kHz}$ and a response time of $<0.5 \mathrm{~ms}$ at laser focus (Baumer Electric AG 2019). To determine its acceleration, an Aaronia GPS Logger with an acquisition rate of $35 \mathrm{~Hz}$ was attached to the sledge. The sledge motion was additionally filmed with a high-speed camera (250-500 frames per second) to optically determine its impact velocity. Further, an accelerometer attached to the sledge allowed a redundant determination of the impact velocity. The final impact velocity was determined by a comparison and calibration of those measurements.

Five water level gauge poles were positioned along the main wave propagation axis to determine the wave amplitudes (Figure 1). The gauge poles were equipped with levelling staffs with a $1 \mathrm{~cm}$ graduation. Additionally, nine bars with coarse markings of $0.5 \mathrm{~m}$ length were placed along the right basin bank to determine the lateral wave run-up. Two bars and one levelling staff were placed at the run-up slope. The water level variation at the gauge poles was then continuously filmed during the experiments with a frame rate of $25 \mathrm{~Hz}$ using a Sony Handycam (HD) and a Canon EOS (4k). The water surface displacement was evaluated from the video recordings with time intervals of $1 \mathrm{~s}$, starting at the time of sledge impact. Additionally, the individual maximum amplitudes between the $1 \mathrm{~s}$ measurements were extracted. The maximum amplitude of the first wave crest at gauge 1 could not be determined, as the water level gauge was not visible due to strong splash formation (Figure 6).

The measurement accuracy depends strongly on the camera resolution, the light conditions and the camera's field of view on the levelling staff. In case of the vertical water level gauge poles, the general measurement accuracy was determined to $\approx \pm 1^{\circ} \mathrm{cm}$ for camera type Canon and $\approx \pm 3 \mathrm{~cm}$ for camera type Sony. 
The measurement accuracy at the run-up slope was determined to $\approx \pm 6 \mathrm{~cm}$ (parallel to the slope). The resulting accuracy corresponds to a measurement accuracy of $\approx \pm 3 \mathrm{~cm}$ in the vertical.

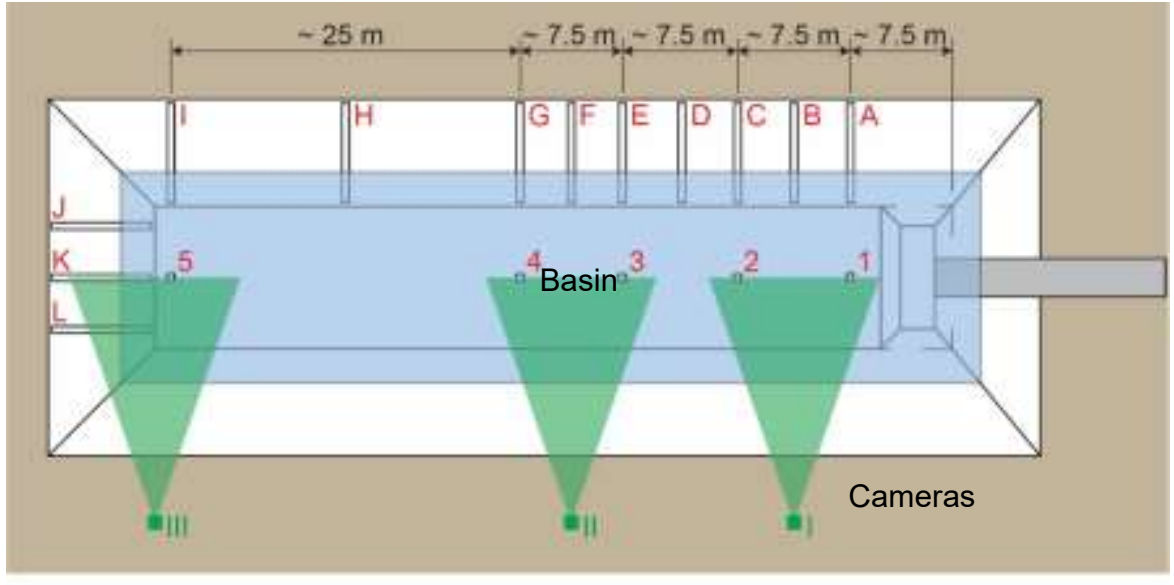

Ramp

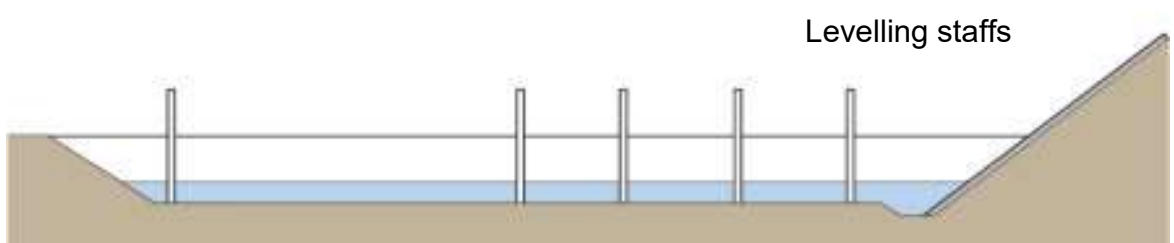

Figure 3. Top and side view of test basin, levelling staffs and camera positions

Test procedure and program

All experiments were conducted as follows:

Positioning of sledge (cable winch) and measurement of sledge position (measurement tape + tachymeter)

Determine the still water level using water level gauge poles and tachymeter measurements

Start of camera recordings and laser sensor measurements

Start signal

Sledge release (remote controlled pawl) and wave recording

After each experiment, the sledge was repositioned using the cable winch. As soon as the still water level recovered, a new experiment could be started. A total of 13 tests were conducted with different initial heights and sledge masses (Table 1). The sledge either had no additional weights (V01-V07) or was loaded with additionally 2 (V08) and 4 tons (V09 to V13). To vary the impact velocity, for some experiments the sledge was released with the cable still attached to the sledge and the winch in idle run. These experiments resulted in significantly lower slide impact velocities (reduction by $\approx 50 \%$ ). Several tests (V02-04, V09-11) were carried out three times to determine the test repeatability.

Table 1. Experimental program of field tests, still water depth $h \approx 1.5 \mathrm{~m}$

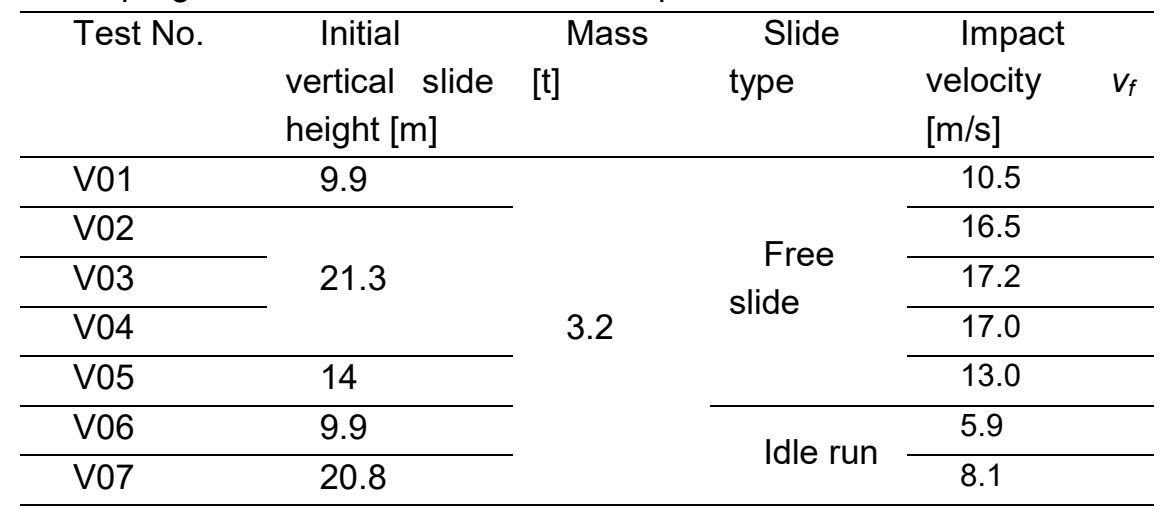




\begin{tabular}{|c|c|c|c|c|}
\hline V08 & 9.4 & 5.2 & & 10.1 \\
\hline V09 & \multirow{3}{*}{21.6} & \multirow{5}{*}{7.2} & \multirow{3}{*}{$\begin{array}{l}\text { Free } \\
\text { slide }\end{array}$} & 15.4 \\
\hline V10 & & & & 16.6 \\
\hline V11 & & & & 17.4 \\
\hline V12 & \multirow{2}{*}{9.9} & & \multirow{2}{*}{ Idle run } & 10.5 \\
\hline V13 & & & & 16.5 \\
\hline
\end{tabular}

\section{LABORATORY TESTS}

Test setup and instrumentation

The scale model tests were conducted at the Laboratory of Hydraulics, Hydrology and Glaciology (VAW) of ETH Zurich. The dimensions of the laboratory test basin allowed a geometrical scale of 1:10 (laboratory : field). All physical parameters were scaled according to Froude's law of similitude.

The laboratory test basin is an idealized, symmetrical reproduction of the field basin (Figure 4). The slide impact ramp had a PVC surface. Depending on the required impact velocity, a wooden or a steel sledge was used. Both sledges had identical dimensions: $26.8 \mathrm{~cm}$ width, $30 \mathrm{~cm}$ length and $15 \mathrm{~cm}$ height. The sledge mass was varied with common weights.

The impact velocity was measured by two laser barriers with a spacing of $20 \mathrm{~cm}$ located $2 \mathrm{~cm}$ and 22 $\mathrm{cm}$ above the still water level. The still water level was kept constant for all experiments at $h=0.15 \mathrm{~m}$.

To determine the wave amplitudes, five ultrasonic distance sensors were located at the same relative positions as the water level gauges 1 to 5 in the gravel pit. The ultrasonic distance sensors registered the change of the water surface with an acquisition rate of $60 \mathrm{~Hz}$ and a measurement accuracy of $\pm 2.0 \mathrm{~mm}$. To determine the run-up height, a measurement tape was attached to the run-up bank in the basin centerline and the water level displacement was filmed by a camera (Canon EOS, HD, frame rate $25 \mathrm{~Hz}$ ). The resulting runup measurement accuracy is $\approx \pm 5 \mathrm{~mm}$.

Test procedure and program

The test procedure and program was equal to the field tests (Section 2.3, Table 1). All 13 tests were reproduced with down-scaled sliding mass and impact velocity. The scaling of mass was based on the geometrical scaling and assuming identical density. Thus, the mass at laboratory scale is 1000 times smaller than in the field. The surface friction of the ramp and sledge differ in field and laboratory. The required sliding length to achieve correct down-scaled impact velocities was therefore determined from preliminary dry testing $\left(v_{f, \text { Laboratory }}=v_{f, \text { Prototype }} / 10^{0.5}\right)$ 


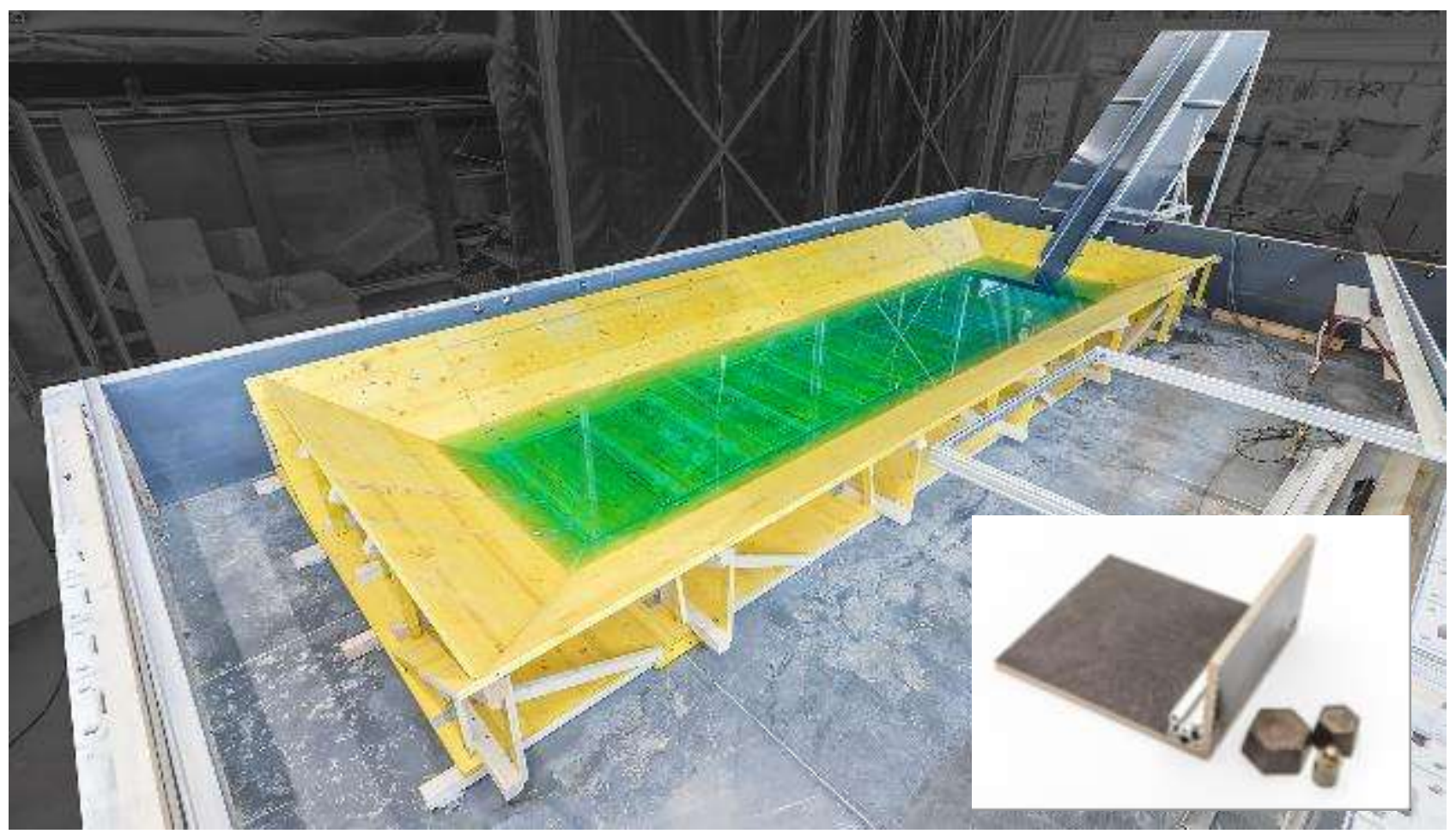

Figure 4. Laboratory test basin and slide ramp (scale 1:10), figure inset: wood sledge with weights

\section{RESULTS}

\section{Evaluated parameter range}

The data evaluation is limited to the first, second and third wave, since wave reflections interacted with the following waves. To compare the results of both field and laboratory tests, all measured parameters were normalized. With the slide front velocity $v_{f}$, the gravity acceleration $g$, the still water depth $h$, the slide thickness $s$, the slide width $b$, the slide mass $m_{s}$, the water density $\rho_{w}$, the free water surface displacement $\eta$ and the time $t$, the resulting parameters are (Figure 5):

Slide Froude number $\mathrm{F}=v_{f} / \sqrt{g h}$

Relative slide thickness $\quad S=s / h$

Relative slide width $B=b / h$

Relative slide mass $\quad M=m_{s} /\left(\rho_{w} b h^{2}\right)$

Impulse product parameter $\quad \mathrm{P}=\mathrm{FS}^{0.5} M^{0.25} \cos ^{0.5}(6 / 7 \alpha)$

Relative wave amplitude $\quad \eta / h$

Relative time $t \sqrt{g / h}$ 

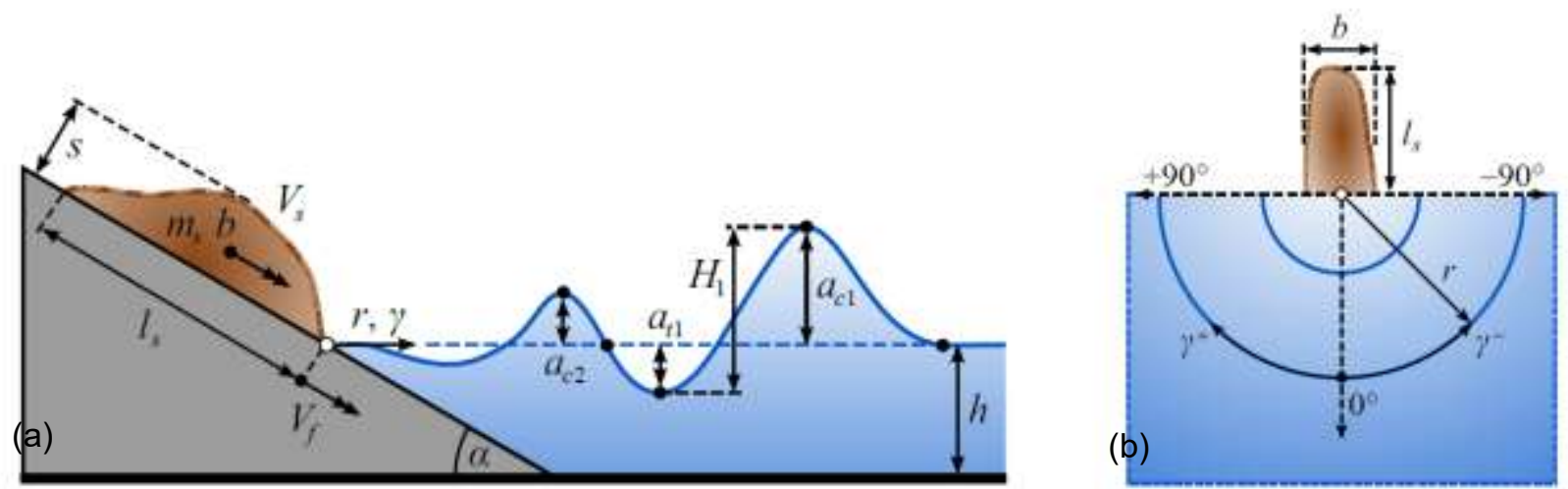

Figure 5. Definition sketch for spatial impulse waves: (a) section view, (b) plan view (Evers 2008)

\section{General process description}

Due to the high sledge impact velocity, a large splash reaches up to $3 / 4$ of the basin length (Figure 6 ). The sledge further propagates into the water body while transferring its momentum to the water. The displaced water volume forms an impact crater and the protruding sledge generates the primary impulse wave. This energy transfer requires a certain time and therefore the wave height increases in the near field of the sledge impact location. The maximum wave height occurs when a maximum of the sledge's energy has been transferred to the water body and the wave has propagated a certain distance from the impact location. Note that the kinetic energy of the sledge is not fully transferred to the water but partially to the basin bottom in the impact zone.

Secondary and tertiary waves result from the impact crater collapse and wave reflection at the slide impact. Wave reflection at the impact and side slopes lead to wave superposition and a significantly irregular water surface. The first and second waves are very steep and therefore start to break shortly after generation such that they finally propagate as long waves with reduced wave height.

The most obvious difference between field and model experiments is the splash characteristics. In the field tests, the large fluid acceleration at sledge impact leads to high turbulence and fluid disintegration and the resulting splash consists of fine water spray. In contrast, the sledge impact velocity in the laboratory tests is reduced by a factor of 3.16 reducing the fluid acceleration and turbulence level at impact. Water surface tension then has a larger effect in relation to the resulting acceleration forces on the fluid such that the water drop size is larger. The laboratory test splash reaches up to $\approx 5 / 4$ of the basin length, i.e. beyond the run-up slope. Particularly in the near field to the impact location, this strong splash formation causes an irregular water surface. A further difference is the basin geometry: as a consequence of a slight asymmetry of the field basin, the reflected waves superpose with a slight offset to the centerline and therefore the maximum amplitudes are not always passing by the installed water level gauges. 

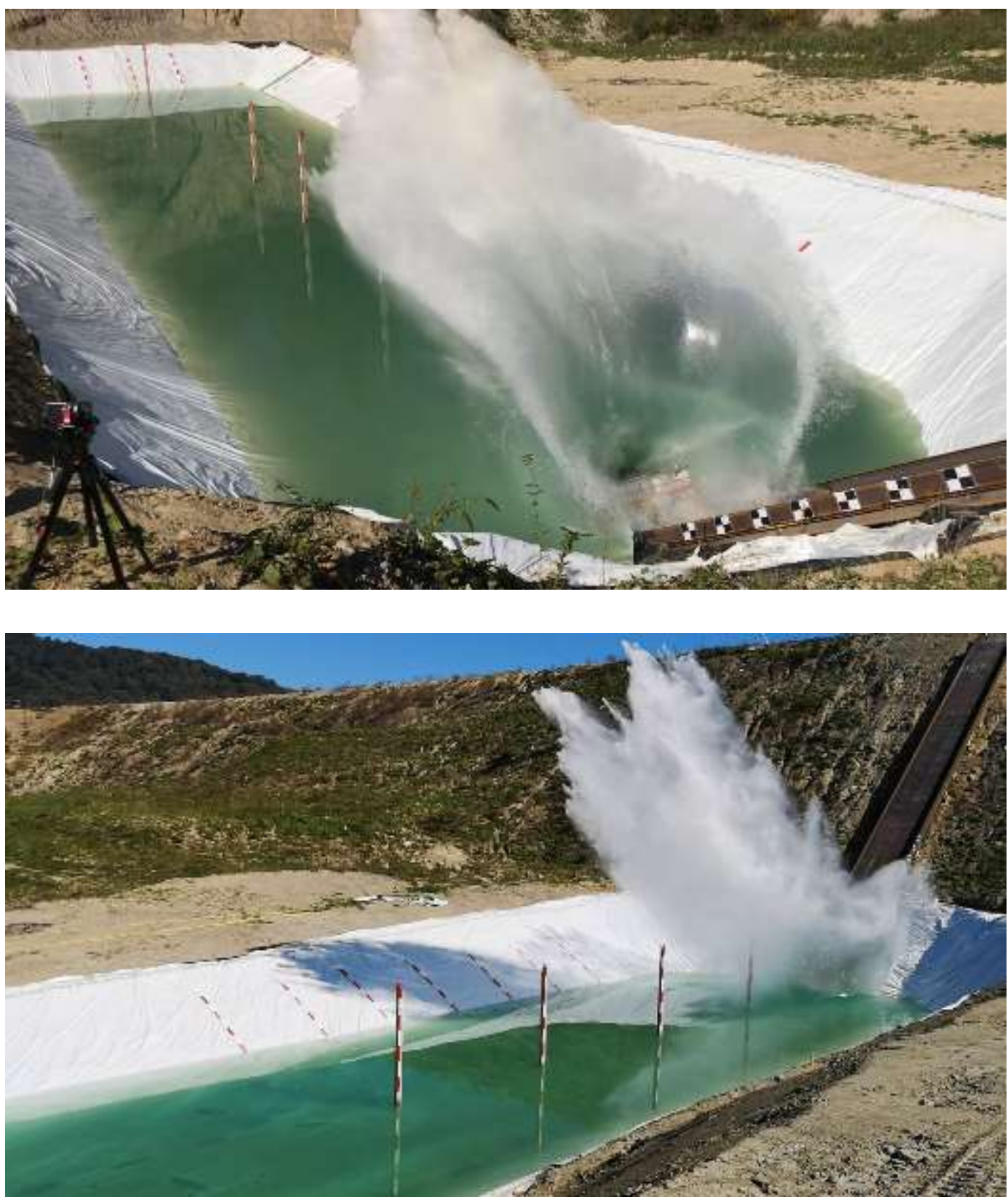

Figure 6. Field test with splash generation after sledge impact

\section{Wave amplitudes}

The maximum wave amplitudes are exemplarily discussed below for field test $\mathrm{V} 11$ (maximum weight and impact velocity). Figure 7 compares wave profiles measured for tests $\mathrm{V} 11$ in the field (dotted line) and laboratory (solid line). The large splash in the near field inhibits a clear reading of the water level gauge 1 , such that the maximum amplitude of the first crest and trough could not be determined. The maximum water surface displacement in the field was measured to $\eta \approx 50 \mathrm{~cm}(\eta / h=0.33)$ at $T=t(g / h)^{0.5} \approx 4.6$. Based on the wave attenuation features, a maximum value for the amplitude of the first wave crest at gauge 1 of $\eta \approx 60 \mathrm{~cm}$ is assumed. During the wave propagation the amplitude of the first wave crest reduces to $\eta \approx 39 \mathrm{~cm}(\eta / h=$ $0.26)$ at $T \approx 9.0$ at gauge 2 and $\eta \approx 13 \mathrm{~cm}(\eta / h=0.87)$ at $T \approx 14.4$ at gauge 3 . The second wave crest amplitude was measured to $\eta \approx 40 \mathrm{~cm}(\eta / h=0.28)$ at gauge 1 at $T \approx 9.2, \eta \approx 39 \mathrm{~cm}(\eta / h=0.26)$ at gauge 2 at $T \approx 15.9$ and $\eta \approx 13 \mathrm{~cm}(\eta / h=0.09)$ at gauge 3 at $T \approx 20.8$. The maximum water surface displacement of the first wave trough was measured at gauge 1 to $\eta \approx-35 \mathrm{~cm}(\eta / h=-0.23)$ at $T \approx 7.2$, resulting in a maximum estimated wave height of $H \approx 95 \mathrm{~cm}(H / h=0.63)$ in the impact region. The first wave trough amplitude 
reduces to $\eta \approx-21 \mathrm{~cm}(\eta / h=-0.14)$ at $T \approx 12.9$ at gauge 2 and $\eta \approx-7 \mathrm{~cm}(\eta / h=-0.05)$ at $T \approx 17.4$ at gauge 3. Due to wave dispersion effects, the first and second waves superpose such that the first wave trough vanishes at $T \approx 23$ at gauge 4 . Gauge 5 is located at the toe of the run-up slope such that the wave profiles are affected by axial wave reflections for $T>35$.
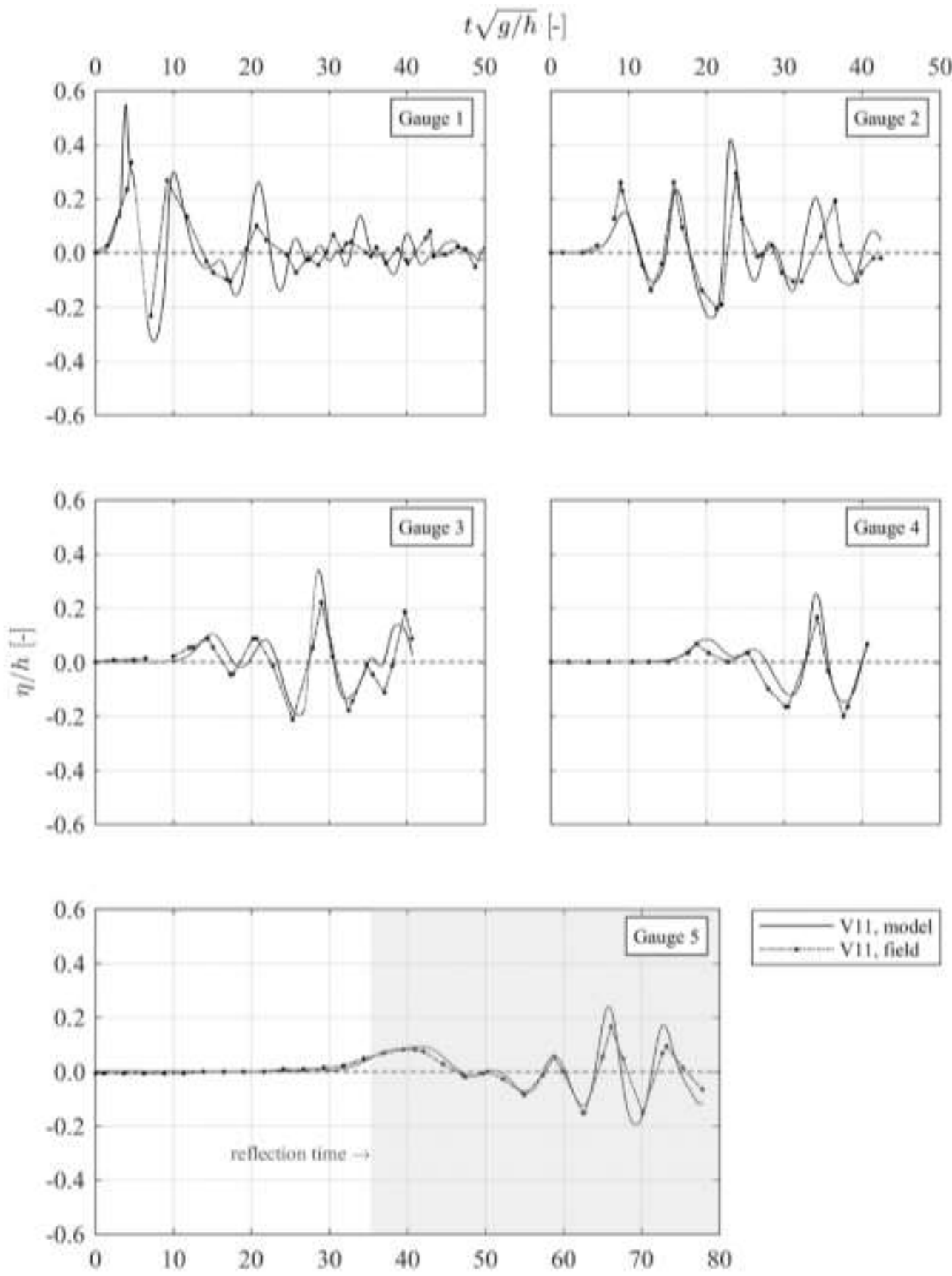

Figure 7. Comparison of relative wave amplitude at relative times measured in field and laboratory for tests V11

The wave profiles of laboratory test V11 (Figure 7, solid line) are generally in good agreement with the corresponding field test, despite some discrepancies. The maximum wave amplitude was measured to $\eta \approx 8.2$ $\mathrm{cm}(\eta / h=0.55)$ at $T \approx 3.9$ at gauge 1 for the first wave crest. Similar to the field test the measurement accuracy close to the impact location is reduced by strong splash formation. With a maximum wave trough amplitude $\eta \approx-5.0 \mathrm{~cm}(\eta / h=-0.33)$ at $T \approx 7.5$ a total wave height of $13.2 \mathrm{~cm}(H / h=0.88)$ results in the impact 
region. The maximum time shift between field and laboratory wave profiles is $0.35 \mathrm{~s}$ at laboratory scale, corresponding to $1.15 \mathrm{~s}$ at field scale.

Slides with smaller P-values generate smaller waves. A comparison of normalized wave profiles measured in the field and the corresponding laboratory test is presented in Figure 8 for test V05. The normalized wave profiles are again in good agreement for the first to the third waves. The largest deviations are observed close to the impact location. At measurement positions with larger distance from the impact location, the wave profile agreement is very good in both amplitudes and temporal appearance. The maximum relative wave amplitude is $\eta / h=0.25$ at $T \approx 4.85$ at gauge 1 and the maximum relative wave height is $H / h=$ 0.43 measured for the first wave at gauge 1 . Analogue comparisons for further test conditions with different sledge masses and impact velocities showed a good agreement as well. In general, the agreement between field and laboratory data is better for slower and lighter sledges.
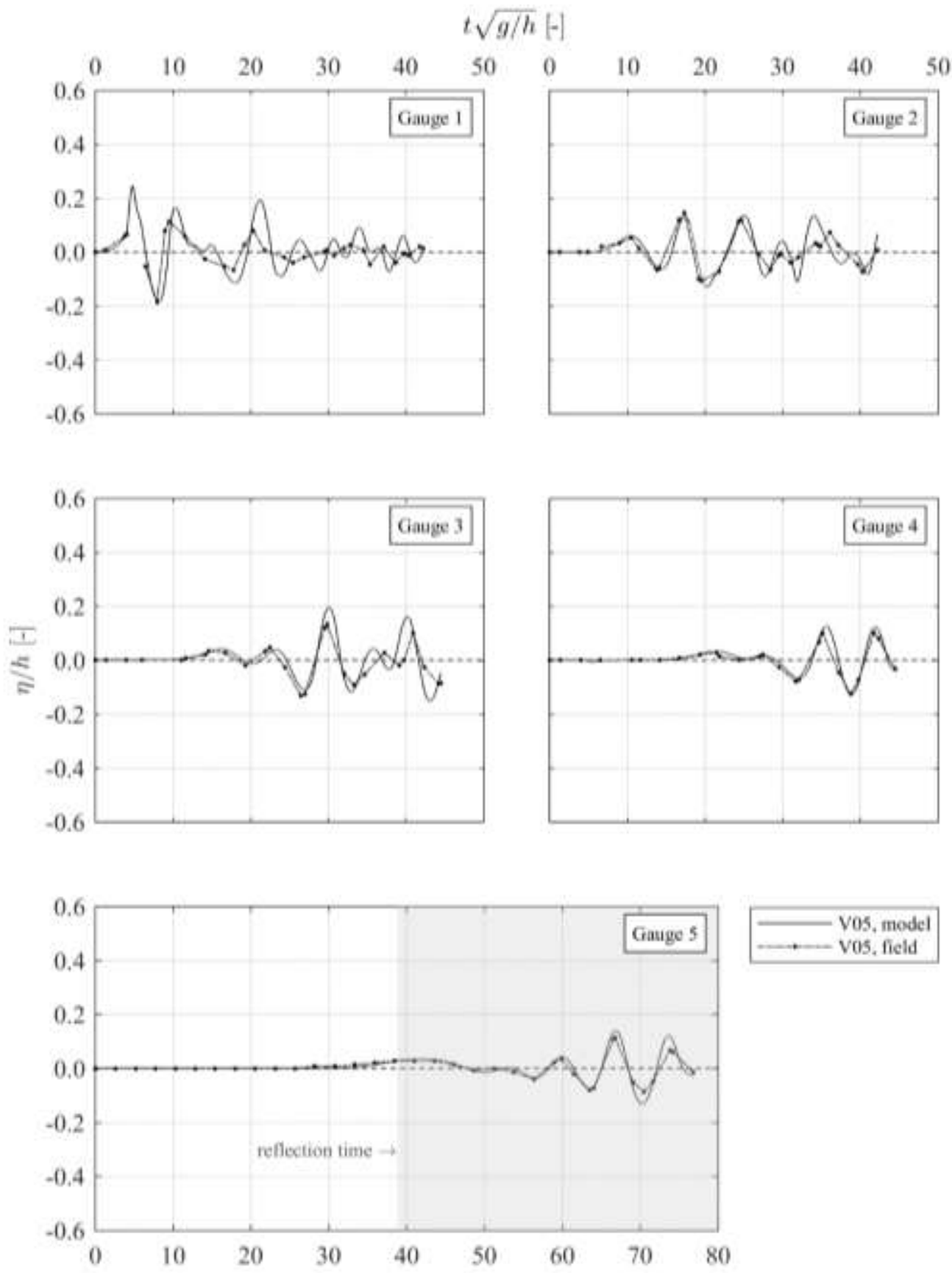
Figure 8. Comparison of relative wave amplitude at relative times measured in field and laboratory for tests V05

Model and scale effects

Models are idealizations of natural conditions. Since an idealization always includes simplifications and small mutations, the impulse wave characteristics may be affected by model effects induced by geometry, roughness and sledge type. Furthermore, possible scale effects may occur because the model tests were conducted according to Froude's law of similitude. As a consequence, scale effects in wave amplitude may arise especially due to the water viscosity, the water surface tension and the water compressibility (Reynolds, Weber and Cauchy Numbers). According to Heller et al. (2008) scale effects due to viscous and surface tension forces in granular impulse wave generation are generally negligible for still water depths $h \geq 0.20 \mathrm{~m}$.

Within the current study it is assumed, that the field tests are not subjected to scale effects. The slide impact process itself resulting in a huge splash has to be evaluated against real conditions when a high mass impacts a water body. A comparison with past events remains challenging, given the lack of available data. The present investigation highlights that there is a good general agreement in the wave profiles of the field and laboratory tests. Especially for the first to the third wave, the normalized wave profiles are in good agreement and the measured wave amplitudes and maximum water surface displacements agree well (Figure 7 and 8). It may therefore be concluded that no major scale effects are present in the laboratory investigation herein supporting the suitability of 3D impulse wave tests conducted at laboratory scale.

\section{CONCLUSIONS}

Large scale field experiments on impulse waves were carried out to investigate possible scale effects and provide calibration and validation data for numerical modelling. The field tests were reproduced in the laboratory at a 1:10 scale and the measured wave characteristics were compared. Due to wave superposition, only the first to the third waves were considered. Wave amplitudes are generally in good agreement for all tests and the maximum amplitudes agree within $\pm 30 \%$. Larger amplitudes show generally a better correlation, whereas smaller amplitudes may be partially affected by the measurement accuracy. The correlation however changes with the propagation distance as the amplitudes decrease and depends on the camera used for evaluation. A difference was especially noted in the splash formation due to the smaller impact velocities in laboratory scale.

Field and laboratory tests are in good agreement and no significant scale effects have been determined. Consequently, laboratory tests are a feasible option to investigate slide induced impulse waves and the acquired results may be classified as robust and reliable. The currently ongoing further evaluation focuses on the wave run-up and the comparison of the field tests to existing computational approaches.

\section{ACKNOWLEDGEMENTS}

The present study was financed by Kraftwerke Oberhasli (KWO) and Innosuisse under the research project FLEXSTOR. The third author is supported by the Swiss Competence Center for Energy Research (SCCER-SoE).

\section{REFERENCES}

Ataie-Ashtiani, B., Malek Mohammadi, S. (2007). Near field amplitude of subaerial landslide generated waves in dam reservoirs. Dam Engineering 17(4): 197-222.

Ehrbar, D., Schmocker, L., Vetsch, D.F., Boes, R.M. (2018). Hydropower Potential in the Periglacial Environment of Switzerland under Climate Change. Sustainability 10, 2794; doi:10.3390/su10082794

Evers, F. (2017). Spatial propagation of landslide generated impulse waves. VAW-Mitteilung 244 (R. Boes, ed.), VAW, ETH Zürich.

Evers, F.M., Boes, R.M. (2019). Impulse Wave Runup on Steep to Vertical Slopes. Journal of Marine Science Engineering, 7(1): 8. 
Falappi, S., Gallati, M. (2007). SPH simulation of water waves generated by granular landslides. Proc. $32^{\text {nd }}$ Congress of IAHR, Venice, 933: 1-10. IAHR, Madrid.

Fritz, H. M., Hager, W. H., Minor, H.-E. (2003). Landslide generated impulse waves. 2. Hydrodynamic impact craters. Experiments in Fluids, 35(6): 520-532.

Fuchs, H. (2017). Solitary Impulse Wave Run-up and Overland Flow. VAW-Mitteilung 221 (R. Boes, ed.), VAW, ETH Zürich.

Heller, V. (2008). Landslide generated impulse waves: Prediction of near field characteristics. VAWMitteilung 204(H.-E. Minor, ed.). VAW, ETH Zürich.

Heller, V., Hager, W. H., Minor, H.-E. (2008). Scale effects in subaerial landslide generated impulse waves. Experiments in Fluids, 44(5): 691-703.

Heller, V., Hager, W.H., Minor, H.-E. (2009). Landslide generated impulse waves in reservoirs: Basics and computation. VAW-Mitteilung 211 (R. Boes, ed.), VAW, ETH Zürich.

Huber, A., Hager, W.H. (1997). Forecasting impulse waves in reservoirs. Proc. 19th Congrès des Grands Barrages, Florence, C.31:993-1005. ICOLD, Paris.

Zweifel, A. (2004). Impulswellen: Effekte der Rutschdichte und der Wassertiefe (Impulse waves: Effects of slide density and water depth). VAW-Mitteilung 186 (H.-E. Minor, ed.), VAW, ETH Zürich (in German). 